\title{
Short communication: Molecular markers for epithelial cells across gastrointestinal tissues and fecal RNA in preweaning dairy calves
}

\author{
F. Rosa, ${ }^{1} \odot$ S. Busato, ${ }^{2} \odot$ F. C. Avaroma, ${ }^{2}$ R. Mohan, ${ }^{1} \odot$ N. Carpinelli, ${ }^{1} \odot$ M. Bionaz, ${ }^{2} \odot$ and J. S. Osorio ${ }^{1 *} \odot$ \\ ${ }^{1}$ Dairy and Food Science Department, South Dakota State University, Brookings, 57007 \\ ${ }^{2}$ Department of Animal and Rangeland Sciences, Oregon State University, Corvallis, 97331
}

\begin{abstract}
The objective of this study was to compare the transcription of gene markers for gastrointestinal (GI) epithelial cells, including fatty acid binding protein 2 (FABP2) and cytokeratin 8 (KRT8), and tight junction complex genes (TJP1, CLDN1,CLDN4) in fecal RNA against several GI tract tissue sections in dairy calves. Eight healthy Jersey calves were euthanized at $5 \mathrm{wk}$ of age, and postmortem samples were collected from rumen, duodenum, jejunum, ileum, large intestine, cecum, and feces for total RNA isolation. Tissues and fecal samples were immediately frozen in liquid nitrogen until RNA isolation. A real-time quantitative PCR analysis was performed using a single standard curve composited of equal amounts of all samples, including cDNA from fecal and GI tract tissues. The mRNA expression of the tight junctions TJP1, CLDN1, and $C L D N 4$ was greater in fecal RNA compared with lower GI tract tissues (i.e., duodenum, jejunum, ileum, large intestine, and cecum). Similar to fecal RNA, rumen tissue had greater expression of tight junctions CLDN1 and CLDN4 than lower GI tract tissues. Similarly, rumen tissue had greater expression of TPJ1 than all lower GI tract tissues except duodenum. The expression of TJP1 and CLDN4 was greater in fecal RNA than in rumen tissue; in contrast, CLDN1 mRNA expression was greater in rumen tissue than in the fecal RNA. The expression of $F A B P 2$ was greater in duodenum in comparison to all tissue except ileum. The mRNA expression of FABP2 in fecal samples was similar to jejunum and ileum. The expression of KRT8 in fecal samples was similar to duodenum, large intestine, and cecum. The fecal RNA had a greater expression of KRT8 in comparison to jejunum and ileum. The rumen tissue had the lowest mRNA expression of KRT8. The expression levels of $F A B P 2, K R T 8$, and tight junction genes observed in fecal transcripts suggest that a considerable
\end{abstract}

Received May 26, 2020.

Accepted August 14, 2020.

*Corresponding author: Johan.Osorio@sdstate.edu amount of RNA derived from GI tract epithelial cells can be detected in fecal RNA, which is in agreement with previous data in neonatal dairy calves and other biological models including humans, rodents, and primates. The greater expression of tight junctions in fecal RNA in comparison to sections of the low GI remains to be understood, and due to the importance of tight junctions in GI physiology, further clarification of this effect is warranted. The similarities in mRNA expression of FABP2 and KRT8 between fecal RNA and intestinal sections add up to the accumulating evidence that fecal RNA can be used to investigate molecular alterations in the GI tract of neonatal dairy calves. Further research in this area should include high-throughput transcriptomic analysis via RNA-seq to uncover novel molecular markers for specific sections of the GI tract of neonates.

Key words: fecal RNA, dairy calves, gene expression

\section{Short Communication}

Gut health in livestock animal production has been commonly associated with animal health and performance involving several distinct physiological and functional parameters, from nutrient digestion and absorption to intestinal barrier function, mucosal immune response, and interactions with the gut microbiome (Kogut and Arsenault, 2016). Neonatal dairy calves are highly susceptible to enteropathogenic diseases because their humoral immunity is under development. At the same time, their gastrointestinal tract (GIT) needs to mature soon after birth, leaving ample room for opportunistic pathogens to target the mucosal epithelium of the small intestine (Malmuthuge et al., 2019). Therefore, understanding the interactions between these diverse GIT physiological features and enteropathogenic diseases is of utmost importance to improve health and well-being in neonatal dairy calves, which can eventually be translated into improved growth performance and feed efficiency.

Several methods have been used to investigate GIT physiology and pathology in livestock animals, includ- 
ing histology and immunostaining (Kim et al., 2011). These methods have commonly required invasive techniques, such as biopsy or collection of postmortem specimens (Bischoff et al., 2014). In addition to the aforementioned methods, molecular-based tools (i.e., PCR and next-generation sequencing) have also been carried out through invasive methods to collect tissue specimens to investigate the biological mechanisms in the gastrointestinal epithelium in neonatal dairy calves (Liang et al., 2016; Malmuthuge and Guan, 2017).

A noninvasive alternative method to biopsies and postmortem collections to study the GIT in neonatal dairy calves was previously developed by Rosa et al. (2018). The method involves the isolation of hostderived RNA from fecal samples to study the transcriptome. In that study, Rosa et al. (2018) demonstrated that host-derived inflammatory transcripts present in fecal RNA from neonatal dairy calves were associated with blood biomarkers of inflammation during a mild diarrhea condition. Further exploration in the fecal RNA approach revealed that host-derived gene expression detected in RNA isolated from fecal material of dairy calves is primarily attributed to epithelial cells rather than immune cells (Rosa and Osorio, 2019). These results are significant because they further suggest that the fecal RNA approach is a reliable tool to draw biological information from the GIT epithelium in neonatal dairy calves.

Among the various fatty acid binding protein (FABP) isoforms, the fatty acid binding protein 2 (FABP2) is specific to the intestinal epithelium (Smathers and Petersen, 2011); thus, it can be considered a molecular biomarker of the small intestine (Thumser et al., 2014; Saqui-Salces et al., 2017; Chaudhary et al., 2018). Similar to FABP2, cytokeratins are proteins highly expressed in the epithelial cells. Among the various cytokeratins, cytokeratin 8 (KRT8) is highly expressed in the intestinal epithelium (Flint et al., 1994). In ruminants, cytokeratin 8 has been used as a specific mammary epithelial marker and used to isolate mammary epithelial cells from the milk (Boutinaud et al., 2015). In monogastric, cytokeratin 8 is associated with survival of intestinal epithelial cells (Habtezion et al., 2011) and adequate structural apical membrane formation of enterocytes (Ameen et al., 2001). Similar to cytokeratins, the tight junction protein complex is an intercellular junction located in the apical membrane of enterocytes, which allows cells to have a highly compacted organization by providing fundamental structural, protection, and permeability functions (Buckley and Turner, 2018). Thus, tight junction proteins are directly associated with intestinal epithelium permeability (Van Itallie et al., 2009; Yu et al., 2014). The tight junctions include transmembrane proteins, such as occludins and claudins, and intracellular proteins, including zonula occludens $(\mathbf{Z O})$ proteins (Buckley and Turner, 2018). The ZO-1, coded by the TJP1 gene, was the first identified tight junction protein (Stevenson et al., 1986). The recognition that ZO-1 was not absolutely required for barrier function and permeability led to the discovery of additional tight junction proteins such as claudins (Furuse et al., 1998). The specific claudins expressed within the GIT vary based on the GIT location, stage of pre- and postnatal development, and presence of disease (Heller et al., 2005; Holmes et al., 2006b). Therefore, the above molecular markers for enterocytes or epithelial cells can be used to assess if fecal RNA is a reliable approach to study GIT.

Although the fecal RNA approach has been used in bovines (Rosa et al., 2018), equines (Coleman et al., 2020), humans (Chapkin et al., 2010), rodents (Whitfield-Cargile et al., 2017), and primates (Sharma et al., 2019), an examination of which GIT section(s) is most likely being resembled in the transcriptional signal observed in fecal RNA has never been performed in bovines. Therefore, our objective was to perform a comparative gene expression analysis using wellestablished enterocytes and epithelial cell markers to partially assess the similarities between RNA isolated from the fecal material and tissues collected from various GIT sections of preweaning dairy calves, including rumen, duodenum, jejunum, ileum, large intestine, and cecum.

All the protocols for this study (protocol no. 4747) were approved by The Institutional Animal Care and Use Committee of the Oregon State University (Corvallis). Details for the original experimental design have been published previously (Rosa et al., 2018). Briefly, 8 healthy male Jersey calves were monitored from birth to 5 wk of age (i.e., preweaned period). All calves were enrolled in the experiment from mid-January to early April 2016. Calves were housed in individual pens and fed twice daily with pasteurized whole cow milk. Calves had ad libitum access to water and a starter grain throughout the experiment. Health evaluations including fecal score (scale 1-4; 1: well-formed feces; 2: soft, pudding-like; 3: pancake batter or runny fecal; 4: liquid or splatters feces) and respiratory score (scale 1-5, 1: normal 2: runny nose, 3: heavy breathing, 4: cough moist, 5: cough dry; Osorio et al., 2012) were recorded daily. None of the calves enrolled in this study received antimicrobial treatment throughout the experiment.

At the end of the trial, calves ( $5 \mathrm{wk}$ old) were euthanized by rapid intravenous injection of a barbiturate (Cat\# NDC 0061-0473-05, Beuthanasia D, Merck Animal Health, Whitehouse Station, NJ) to harvest gastrointestinal tissues (i.e., ruminal tissue, duodenum, jejunum, ileum, large intestine, and cecum) for 
gene expression analysis. The samples from the small intestine were collected as follows: duodenum samples were collected from $10 \mathrm{~cm}$ distal to the pylorus; jejunum tissue samples were collected $1 \mathrm{~m}$ anterior to the rumen between 2 distinct Peyer's patches; and ileum tissue samples were collected from the proximal end of the ileo-cecal fold. The large intestine specimens were collected from the mid-spiral colon section. Tissues were harvested using sterile scalpels and forceps and immediately cleaned with RNase decontamination solution (RNaseZap, AM9780, Thermo Fisher Scientific, Waltham, MA), quickly blotted with sterile gauze to remove residual blood, and snap-frozen in liquid nitrogen. Additionally, before the euthanasia procedure, a fresh fecal sample (fecal score $=1$ or 2 ) was collected from each calf through rectum stimulation into a 2.0-mL cryogenic vial (Cat. \# 430488, Corning Inc., Corning, NY) and immediately snap-frozen in liquid nitrogen. All samples were then stored at $-80^{\circ} \mathrm{C}$ until RNA extraction.

The fecal RNA isolation was conducted using the same protocol, as described in Rosa et al. (2018). Briefly, $\sim 200 \mathrm{mg}$ of fecal sample was used for RNA isolation using a Trizol-based (Ambion, Carlsbad, CA, Cat. No. 15596018) method along with the RNeasy Plus Mini Kit (Qiagen, Hilden, Germany, Cat. No. 74134), following the manufacturer's instructions with some modifications. The overall RNA concentration for all fecal samples was $428.38 \pm 37.92 \mathrm{ng} / \mu \mathrm{L}$, and purity (260/280 ratio) was $1.97 \pm 0.08$ determined via Nanodrop (Thermo Fisher Scientific). A sample of 100 mg of tissue from each of the GIT tissues was used for RNA isolation, and the RNA concentration and purity determined via Nanodrop was $1,868.53 \pm 61.23 \mathrm{ng} / \mu \mathrm{L}$ and $2.09 \pm 0.02$, respectively. The RNA integrity was assessed using the TapeStation (Agilent Technologies, Santa Clara, CA), and the final RIN number was 7.0 \pm 0.5 and $5.9 \pm 0.8$ for GIT tissues and fecal samples, respectively.

Details regarding primers source and sequencing results are presented in Table 1 and in Supplemental Table S1 (https://doi.org/10.3168/jds.2020-18955), respectively. The complementary DNA (cDNA) synthesis and quantitative PCR ( $\mathbf{q P C R}$ ) were performed according to the protocol described by Rosa et al. (2018) with some modifications. Each cDNA was synthesized by reverse transcription using 500 and $100 \mathrm{ng}$ of RNA for fecal and GIT tissues, respectively. The cDNA was then diluted 1:3 (vol:vol) with DNase/RNase-free water. The qPCR reaction was performed in a QuantStudio 6 Flex Real-Time PCR System (Applied Biosystems) in a MicroAmp Optical 384-well Reaction Plate (Applied Biosystems) using the following conditions: $2 \mathrm{~min}$ at $50^{\circ} \mathrm{C}, 10 \mathrm{~min}$ at $95^{\circ} \mathrm{C}$, and 40 cycles with $15 \mathrm{~s}$ at $95^{\circ} \mathrm{C}$ followed by $1 \mathrm{~min}$ at $60^{\circ} \mathrm{C}$. The presence of a single PCR product was verified by the dissociation protocol using incremental temperatures to $95^{\circ} \mathrm{C}$ for $15 \mathrm{~s}$ and $65^{\circ} \mathrm{C}$ for $15 \mathrm{~s}$. Data were calculated using the QuantStudio Real-Time PCR software v1.3 with the formula Quantity $=10^{\text {(Ct-intercept/slope) }}$, where intercept and slope were derived from the standard curve and $\mathrm{Ct}$ values from each reaction. The $\mathrm{Ct}$ values were corrected for the efficiency of amplification based on a 6-point standard curve (Bustin 2002) plus the nontemplate control and normalized by the geometric mean of the most robust internal control genes (Vandesompele et al., 2002). The standard curve was composed of equal aliquots of cDNA from each sample (not diluted), including cDNA from fecal and GIT tissues. The standard curve was diluted 1:3 with DNase/RNase-free water. The internal control genes (ICG) assessed in this experiment were $\beta$-2-microglobulin (B2M), $\beta$-actin $(A C T B)$, glyceraldehyde 3-phosphate dehydrogenase $(G A P D H)$, ribosomal protein 9 (RPS9), ribosomal protein S15A (RPS15A), and peptidylprolyl isomerase A (PPIA). The stability of the ICG was assessed using the geNorm software (Vandesompele et al., 2002), with the lowest pairwise variation of 0.21 using all 6 ICG. Therefore, the geometric mean of all 6 ICG was used to normalize the expression of the target genes. The target genes evaluated in this study were the intestinal epithelial cell marker FABP2, the epithelial cell marker KRT8, TJP1, and 2 claudins genes, CLDN1 and CLDN4, members of the tight junction complex. Data were analyzed using the PROC MIXED procedure of SAS 9.4 (SAS Institute, Inc., Cary, NC). The model included the type of sample (fecal and the various GIT tissues) as a fixed effect and calf as random. Statistical significance and tendencies were declared at $P \leq 0.05$ and $0.05 \leq P \leq 0.10$, respectively.

In this study, we observed that the expression of tight junctions TJP1, CLDN1, and CLDN4 was similar $(P>$ $0.05)$ across the small intestine sections and the cecum and large intestine (Figure 1). The TJP1 expression was similar $(P=0.12)$ between the duodenum and rumen tissue. However, the fecal samples had the greatest $(P$ $<0.01$ ) expression of the TJP1 and CLDN4 when compared with all the other small intestine sections, cecum, large intestine, and rumen tissue (Figure 1). The rumen tissue had greater $(P \leq 0.04)$ expression of the TJP1 than jejunum, ileum, large intestine, and cecum and the greatest expression of CLDN1 (Figure 1). These tight junctions contribute to the exclusion of pathogens and large molecules through paracellular transport and allow the diffusion of ions, water, and small molecules (Wells et al., 2017). In this context, gastrointestinal disorders, including food allergies and celiac disease, have been associated with hyperpermeability of the intesti- 
Table 1. Gene symbol, hybridization position, sequence, and amplicon size of primers for Bos taurus used to analyze gene expression

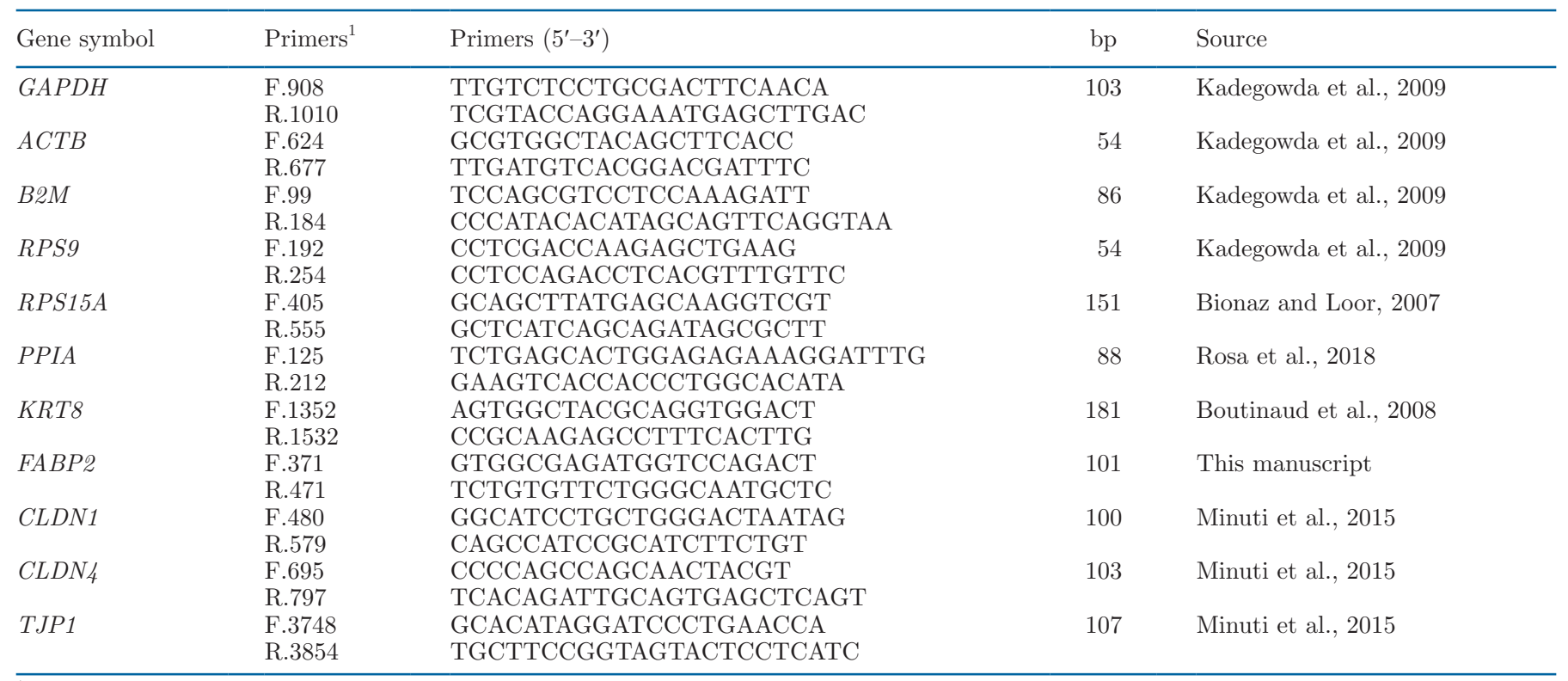

${ }^{1} \mathrm{~F}=$ forward; $\mathrm{R}=$ reverse.

nal epithelium (Bischoff et al., 2014). In the intestinal epithelium, the tight junction proteins claudin-1 and claudin- 4 have been reported to decrease the paracellular permeability (Angelow and $\mathrm{Yu}, 2009$ ). The mRNA expression of tight junctions in our study was similar with other reports in the literature, where the expression of $C L D N 1$ did not differ among gastrointestinal regions of dairy calves during the weaning period from milk to solid feed (Malmuthuge et al., 2013), as well as in dairy calves of 4 wk old (Walker et al., 2015). Also, a study conducted in mice demonstrated that among the known claudins (from claudin-1 to claudin-19), the CLDN1, CLDN4, CLDN5, CLDN9, and CLDN10 were the lowest expressed in the gastrointestinal regions (i.e., duodenum, jejunum, ileum, cecum, and colon; Holmes et al., 2006a). Additionally, Holmes et al. (2006a) observed no differences in the expression of those claudins throughout the gut regions. Future research in this area should focus on testing the responsiveness of tight junction genes detected in fecal RNA during diarrhea events to demonstrate the reliability of fecal gene expression to evaluate gut permeability.

The greater mRNA expression of tight junction genes in rumen tissue, when compared with lower GIT tissues, was evident, and this might be associated with morphological differences between the ruminal and the intestinal epithelium. The rumen epithelium consists of stratified cells that, with leaf-like papillae, increase the absorptive surface area. It is well established that the transport of nutrients across the rumen epithelium is mediated by a gradient concentration difference (Sehested et al., 1999; Shen et al., 2004), which also implies the presence of a permeability barrier including tight junction proteins at the stratum granulosum level. In contrast to the multilayered stratified squamous epithelium found in the rumen, the small intestine, cecum, and large intestine consist of a simple columnar epithelium that encompass mucus-secreting cells, resulting in a dense mucus layer (Steele et al., 2016). Although the differences in tight junction mRNA expression between ruminal and intestinal epithelium seem to be morphological, the reason for the high level of tight junction (including TJP1, and claudins 1-4) mRNA expression in the fecal of preweaned calves observed in the current study remains unknown.

Keratins are the largest family of cellular intermediate filament proteins and are predominant in epithelial cells (Iyer et al., 2013). Among keratins, keratin 8 has been associated with mammary epithelial cells and small intestinal mucosa (Moll et al., 2008). Kaeffer et al. (2007) used keratin 8 as a marker to measure exfoliated epithelial cells in the feces of preterm infants with the aim to use fecal samples to investigate GIT physiology. Additionally, keratin 8 expression was used as a marker for intestinal epithelial cells in dairy cows (Koch et al., 2019). In the current study, KRT8 expression was similar between the duodenum and fecal samples $(P=0.18)$, and KRT8 was similarly expressed in the cecum and large intestine when compared with the feces mRNA $(P=0.30)$. However, the expression of KRT8 was greater $(P \leq 0.02)$ in feces than in the jejunum and ileum tissues (Figure 2).

Fatty acid binding proteins are cytosolic proteins found in several tissues, including intestine, liver, and 

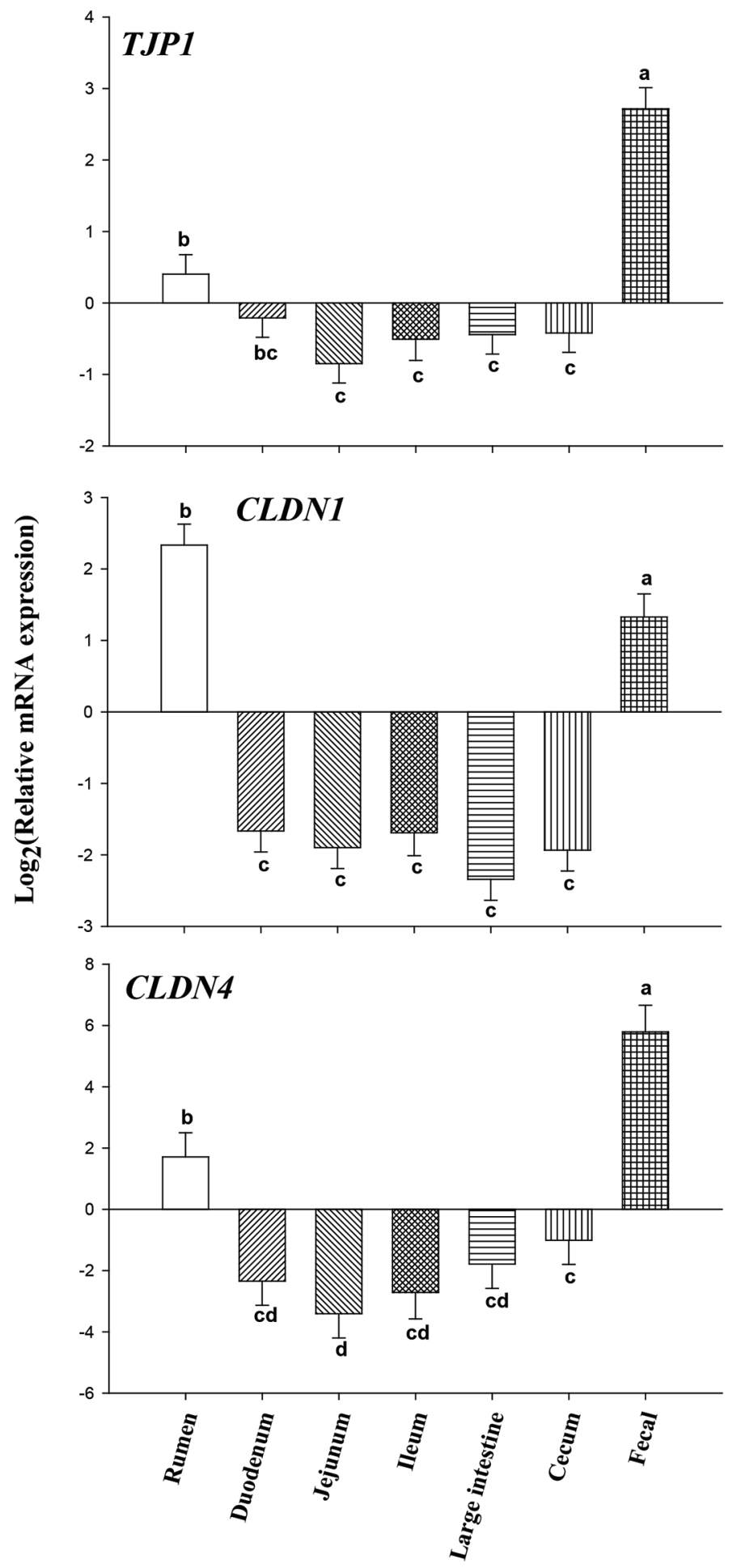

Figure 1. Tight junction protein ZO-1 (TJP1), claudin-1 (CLDN1), and claudin-4 (CLDN4) relative mRNA expression ( $\log _{2}$ scale) in rumen, gastrointestinal tract tissues, and in total fecal RNA isolated from Jersey calves with 5 wk of age $(\mathrm{n}=8)$. Values are means; error bars represent SE. ${ }^{\text {a-d }}$ Means without a common letter differ $(P \leq 0.05)$. heart, and they are necessary for intracellular binding and transport of fatty acids (Storch and Thumser, 2000). Among the 9 FABP identified, the FABP2 is highly expressed in the small intestine, and it has been identified as a specific marker for intestinal epithelium in humans (Levy et al., 2001). In monogastrics, the mRNA FABP2 expression in the small intestine of pigs was associated with intestinal permeability (Schroyen et al., 2012), and loss of enterocytes was correlated with a downregulation of $F A B P 2$ expression in the jejunal mucosa of broiler chickens (Chen et al., 2015). In the present study (Figure 2), the mRNA expression of $F A B P 2$ in small intestinal tissues was consistent with prior data in other livestock models, where $F A B P 2$ was

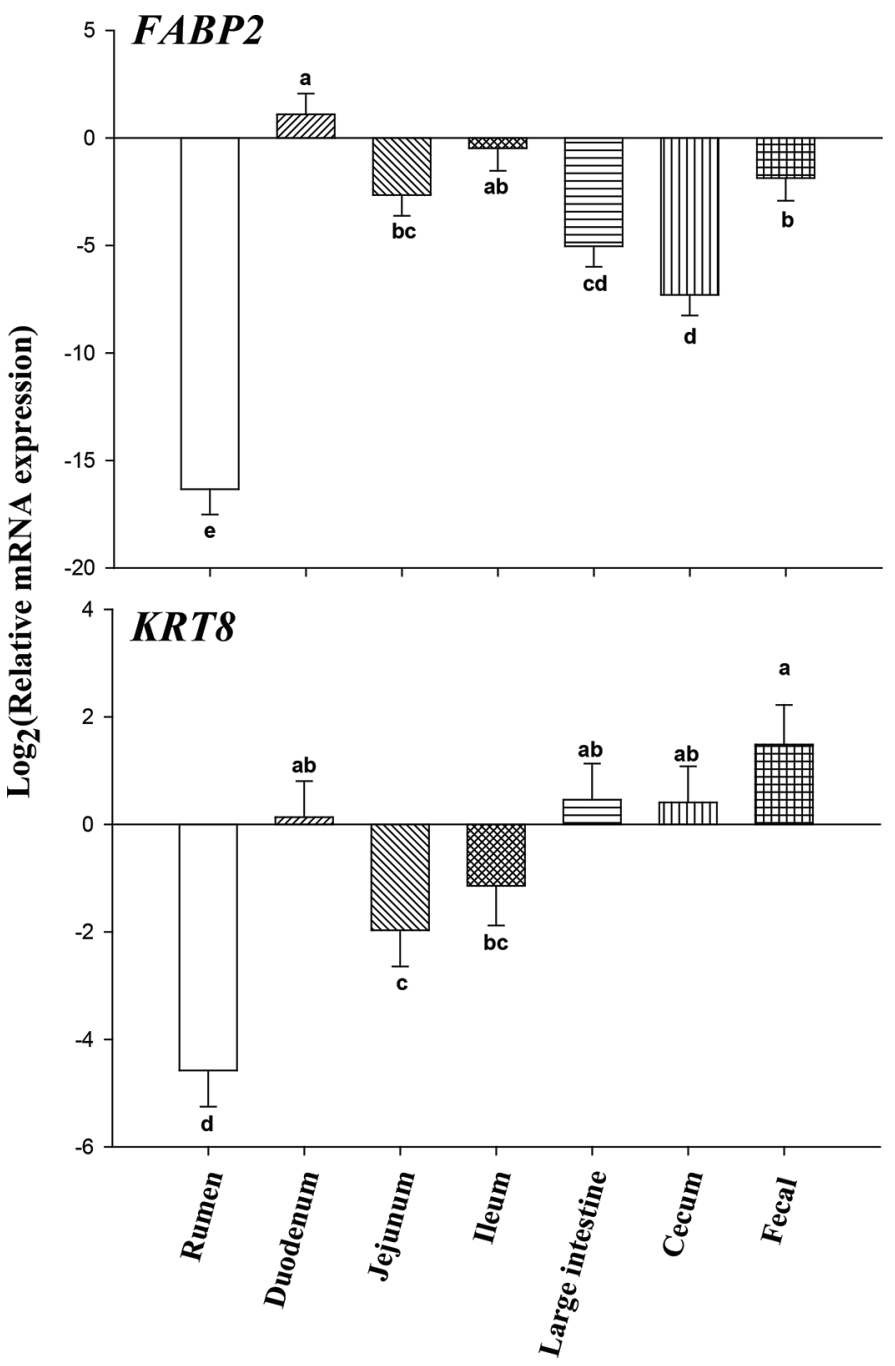

Figure 2. Fatty acid binding protein $2(F A B P 2)$ and keratin 8 (KRT8) relative mRNA expression ( $\log _{2}$ scale) in rumen, gastrointestinal tract tissues, and in total fecal RNA isolated from Jersey calves with 5 wk of age $(n=8)$. Values are means; error bars represent SE. ${ }^{\text {add }}$ Means without a common letter $\operatorname{differ}(P \leq 0.05)$. 
highly expressed in the small intestine than other sections in the GIT. In addition, FABP2 was similarly expressed between fecal samples and jejunum $(P=$ $0.58)$ and ileum $(P=0.36)$, suggesting that $F A B P 2$ expression in fecal RNA is a suitable biomarker or indicator of the amount of intestinal epithelium transcripts present in fecal RNA.

Taken together, our findings demonstrate a difference in the level of mRNA expression of genes encoding tight junction proteins between the ruminal and intestinal epithelia of dairy calves. And, this can be attributed to the differential epithelial cell layer structures between these sections of the GIT. Regarding the specific epithelial cell markers, the low abundance of KRT8 and FABP2 mRNA within ruminal samples (Table 2) is an indication that these markers are highly specific to intestinal epithelial cells in ruminants, which consistent with a high specificity of these intestinal markers observed in humans (Wiercinska-Drapalo et al., 2008; Gajda and Storch, 2015).

\section{CONCLUSIONS}

The expression levels of FABP2, KRT8, and tight junction genes observed in fecal transcripts suggest that a considerable amount of RNA derived from epithelial cells can be detected in fecal RNA, which is in agreement with previous data in neonatal dairy calves from our group and other biological models including humans, horses, rodents, and primates. The greater expression of tight junctions in fecal RNA in comparison to the various sections of the low GIT remains to be understood. Due to the importance of tight junctions in GIT physiology, further clarification of this effect is warranted. The transcriptional resemblance between fecal RNA and GIT should be evaluated in response to physiological conditions (e.g., diarrhea), which will be a more accurate approach. The similarities in mRNA expression of FABP2 and KRT8 between fecal RNA and intestinal sections add up to the accumulating evidence that fecal RNA can be used to investigate mo-

Table 2. Slope, efficiency (E) of amplification, coefficient of determination of the standard curve $\left(\mathrm{R}^{2}\right)$, median cycle threshold (Ct) of quantitative reverse transcription PCR, and relative mRNA abundance

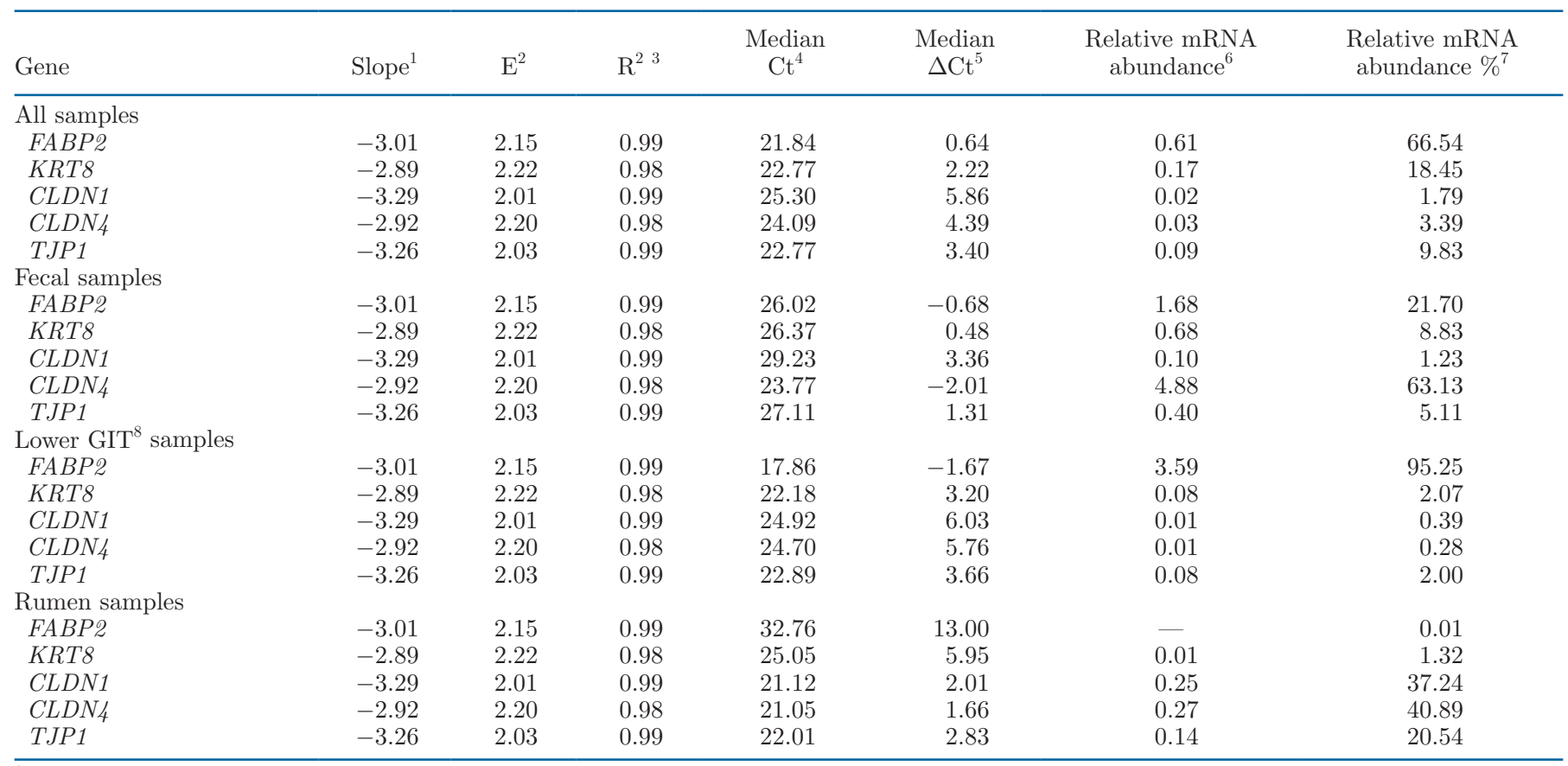

${ }^{1}$ Slope of the 6-point standard curve.

${ }^{2}$ Efficiency of amplification $\left[\mathrm{E}=10^{(-1 / \text { slope })}\right]$.

${ }^{3}$ Coefficient of determination of the standard curve $\left(\mathrm{R}^{2}\right)$.

${ }^{4}$ Median $\mathrm{Ct}=$ median cycle threshold, which is defined as the number of cycles required for the fluorescent signal to cross the threshold (i.e., exceed background level), and the amount of target nucleic acid in the sample is inversely correlated with Ct cycles (i.e., the greater the amount of target nucleic acid, the lower the $\mathrm{Ct}$ cycles will be required).

${ }^{5}$ Median $\Delta \mathrm{Ct}$ is calculated as (Ct gene $=$ geometrical mean of $\mathrm{Ct}$ internal controls).

${ }^{6}$ Relative mRNA abundance $=1 /$ Efficiency ${ }^{\text {Median } \Delta \mathrm{Ct}}$.

${ }^{7}$ Relative mRNA abundance $(\%)=($ relative mRNA abundance of specific gene/Erelative mRNA abundance of all genes $) \times 100$.

${ }^{8} \mathrm{GIT}=$ gastrointestinal tract. 
lecular alterations in the GIT tract of neonatal dairy calves. Further research in this area should include high-throughput transcriptomic analysis via RNA-seq to uncover novel molecular markers for specific sections of the GI tract of neonates.

\section{ACKNOWLEDGMENTS}

The authors gratefully acknowledge the Oregon Agricultural Experiment Station (Corvallis, OR, project no. ORE00144) and the South Dakota Agricultural Experimental Station (Brookings, SD, project no. SD00H612-16) for the financial support for this research. The authors thank Seth Spencer of the Oregon State University Dairy Research Center for help with animal management. The authors have not stated any conflicts of interest.

\section{REFERENCES}

Ameen, N. A., Y. Figueroa, and P. J. Salas. 2001. Anomalous apical plasma membrane phenotype in CK8-deficient mice indicates a novel role for intermediate filaments in the polarization of simple epithelia. J. Cell Sci. 114:563-575.

Angelow, S., and A. S. Yu. 2009. Structure-function studies of claudin extracellular domains by cysteine-scanning mutagenesis. J. Biol. Chem. 284:29205-29217. https://doi.org/10.1074/jbc.M109 .043752 .

Bionaz, M., and J. J. Loor. 2007. Identification of reference genes for quantitative real-time PCR in the bovine mammary gland during the lactation cycle. Physiol. Genomics 29:312-319. https://doi .org/10.1152/physiolgenomics.00223.2006.

Bischoff, S. C., G. Barbara, W. Buurman, T. Ockhuizen, J. D. Schulzke, M. Serino, H. Tilg, A. Watson, and J. M. Wells. 2014. Intestinal permeability-A new target for disease prevention and therapy. BMC Gastroenterol. 14:189. https://doi.org/10.1186/s12876-014 $-0189-7$.

Boutinaud, M., M. H. Ben Chedly, E. Delamaire, and J. GuinardFlament. 2008. Milking and feed restriction regulate transcripts of mammary epithelial cells purified from milk. J. Dairy Sci. 91:988998. https://doi.org/10.3168/jds.2007-0587.

Boutinaud, M., L. Herve, and V. Lollivier. 2015. Mammary epithelial cells isolated from milk are a valuable, non-invasive source of mammary transcripts. Front. Genet. 6:323. https://doi.org/10 .3389 /fgene.2015.00323.

Buckley, A., and J. R. Turner. 2018. Cell biology of tight junction barrier regulation and mucosal disease. Cold Spring Harb. Perspect. Biol. 10:a029314. https://doi.org/10.1101/cshperspect.a029314.

Bustin, S. A. 2002. Quantification of mRNA using real-time reverse transcription PCR (RT-PCR): Trends and problems. J. Mol. Endocrinol. 29:23-39.

Chapkin, R. S., C. Zhao, I. Ivanov, L. A. Davidson, J. S. Goldsby, J. R. Lupton, R. A. Mathai, M. H. Monaco, D. Rai, W. M. Russell, S. M. Donovan, and E. R. Dougherty. 2010. Noninvasive stoolbased detection of infant gastrointestinal development using gene expression profiles from exfoliated epithelial cells. Am. J. Physiol. Gastrointest. Liver Physiol. 298:G582-G589. https://doi.org/10 .1152 /ajpgi.00004.2010.

Chaudhary, N., H. Agrawal, M. Pandey, S. Onteru, and D. Singh. 2018. Development and characterization of 2-dimensional culture for buffalo intestinal cells. Cytotechnology 70:361-373. https://doi .org/10.1007/s10616-017-0151-y.

Chen, J., G. Tellez, J. D. Richards, and J. Escobar. 2015. Identification of potential biomarkers for gut barrier failure in broiler chickens. Front. Vet. Sci. 2:14. https://doi.org/10.3389/fvets.2015 .00014 .

Coleman, M. C., C. Whitfield-Cargile, N. D. Cohen, J. L. Goldsby, L. Davidson, A. M. Chamoun-Emanuelli, I. Ivanov, S. Eades, N. Ing, and R. S. Chapkin. 2020. Non-invasive evaluation of the equine gastrointestinal mucosal transcriptome. PLoS One 15:e0229797. https://doi.org/10.1371/journal.pone.0229797.

Flint, N., P. W. Pemberton, R. W. Lobley, and G. S. Evans. 1994. Cytokeratin expression in epithelial cells isolated from the crypt and villus regions of the rodent small intestine. Epithelial Cell Biol. 3:16-23.

Furuse, M., K. Fujita, T. Hiiragi, K. Fujimoto, and S. Tsukita. 1998. Claudin-1 and -2 : Novel integral membrane proteins localizing at tight junctions with no sequence similarity to occludin. J. Cell Biol. 141:1539-1550. https://doi.org/10.1083/jcb.141.7.1539.

Gajda, A. M., and J. Storch. 2015. Enterocyte fatty acid-binding proteins (FABPs): different functions of liver and intestinal FABPs in the intestine. Prostaglandins Leukot. Essent. Fatty Acids 93:9-16. https://doi.org/10.1016/j.plefa.2014.10.001

Habtezion, A., D. M. Toivola, M. N. Asghar, G. S. Kronmal, J. D. Brooks, E. C. Butcher, and M. B. Omary. 2011. Absence of keratin 8 confers a paradoxical microflora-dependent resistance to apoptosis in the colon. Proc. Natl. Acad. Sci. USA 108:1445-1450. https: //doi.org/10.1073/pnas.1010833108.

Heller, F., P. Florian, C. Bojarski, J. Richter, M. Christ, B. Hillenbrand, J. Mankertz, A. H. Gitter, N. Burgel, M. Fromm, M. Zeitz, I. Fuss, W. Strober, and J. D. Schulzke. 2005. Interleukin-13 is the key effector Th2 cytokine in ulcerative colitis that affects epithelial tight junctions, apoptosis, and cell restitution. Gastroenterology 129:550-564. https://doi.org/10.1016/j.gastro.2005.05.002.

Holmes, J. L., C. M. Van Itallie, J. E. Rasmussen, and J. M. Anderson. 2006a. Claudin profiling in the mouse during postnatal intestinal development and along the gastrointestinal tract reveals complex expression patterns. Gene Expr. Patterns 6:581-588. https://doi .org/10.1016/j.modgep.2005.12.001.

Holmes, J. L. C. M. Van Itallie, J. E. Rasmussen, and J. M. Anderson. 2006b. Claudin profiling in the mouse during postnatal intestinal development and along the gastrointestinal tract reveals complex expression patterns. Gene Expr. Patterns 6:581-588. https://doi .org/10.1016/j.modgep.2005.12.001.

Iyer, S. V., P. P. Dange, H. Alam, S. S. Sawant, A. D. Ingle, A. M. Borges, N. V. Shirsat, S. N. Dalal, and M. M. Vaidya. 2013. Understanding the role of keratins 8 and 18 in neoplastic potential of breast cancer derived cell lines. PLoS One 8:e53532. https://doi .org/10.1371/journal.pone.0053532.

Kadegowda, A. K., M. Bionaz, B. Thering, L. S. Piperova, R. A. Erdman, and J. J. Loor. 2009. Identification of internal control genes for quantitative polymerase chain reaction in mammary tissue of lactating cows receiving lipid supplements. J. Dairy Sci. 92:20072019. https://doi.org/10.3168/jds.2008-1655.

Kaeffer, B., C. des Robert, M. C. Alexandre-Gouabau, A. Pagniez, A. Legrand, V. Amarger, A. Kuster, H. Piloquet, M. Champ, I. le Huerou-Luron, and J. C. Roze. 2007. Recovery of exfoliated cells from the gastrointestinal tract of premature infants: A new tool to perform "noninvasive biopsies?" Pediatr. Res. 62:564-569. https:// doi.org/10.1203/PDR.0b013e318155a402.

Kim, H. J., J. G. Park, J. Matthijnssens, J. H. Lee, Y. C. Bae, M. M. Alfajaro, S. I. Park, M. I. Kang, and K. O. Cho. 2011. Intestinal and extra-intestinal pathogenicity of a bovine reassortant rotavirus in calves and piglets. Vet. Microbiol. 152:291-303. https://doi.org/ 10.1016/j.vetmic.2011.05.017.

Koch, F., U. Thom, E. Albrecht, R. Weikard, W. Nolte, B. Kuhla, and C. Kuehn. 2019. Heat stress directly impairs gut integrity and recruits distinct immune cell populations into the bovine intestine. Proc. Natl. Acad. Sci. USA 116:10333-10338. https://doi.org/10 .1073/pnas.1820130116.

Kogut, M. H., and R. J. Arsenault. 2016. Editorial: Gut health: The new paradigm in food animal production. Front. Vet. Sci. 3:71. https://doi.org/10.3389/fvets.2016.00071.

Levy, E., D. Ménard, E. Delvin, S. Stan, G. Mitchell, M. Lambert, E. Ziv, J. C. Feoli-Fonseca, and E. Seidman. 2001. The polymorphism 
at codon 54 of the FABP2 gene increases fat absorption in human intestinal explants. J. Biol. Chem. 276:39679-39684. https://doi .org/10.1074/jbc.M105713200.

Liang, G., N. Malmuthuge, H. Bao, P. Stothard, P. J. Griebel, and L. L. Guan. 2016. Transcriptome analysis reveals regional and temporal differences in mucosal immune system development in the small intestine of neonatal calves. BMC Genomics 17:602. https:/ /doi.org/10.1186/s12864-016-2957-y.

Malmuthuge, N., and L. L. Guan. 2017. Understanding the gut microbiome of dairy calves: Opportunities to improve early-life gut health. J. Dairy Sci. 100:5996-6005. https://doi.org/10.3168/jds .2016-12239.

Malmuthuge, N., M. Li, L. A. Goonewardene, M. Oba, and L. L. Guan. 2013. Effect of calf starter feeding on gut microbial diversity and expression of genes involved in host immune responses and tight junctions in dairy calves during weaning transition. J. Dairy Sci. 96:3189-3200. https://doi.org/10.3168/jds.2012-6200.

Malmuthuge, N., G. Liang, P. J. Griebel, and L. L. Guan. 2019. Taxonomic and functional compositions of the small intestinal microbiome in neonatal calves provide a framework for understanding early life gut health. Appl. Environ. Microbiol. 85:e02534-18. https:/ /doi.org/10.1128/AEM.02534-18.

Minuti, A., A. Palladino, M. J. Khan, S. Alqarni, A. Agrawal, F. Piccioli-Capelli, F. Hidalgo, F. C. Cardoso, E. Trevisi, and J. J. Loor. 2015. Abundance of ruminal bacteria, epithelial gene expression, and systemic biomarkers of metabolism and inflammation are altered during the peripartal period in dairy cows. J. Dairy Sci. 98:8940-8951. https://doi.org/10.3168/jds.2015-9722.

Moll, R., M. Divo, and L. Langbein. 2008. The human keratins: Biology and pathology. Histochem. Cell Biol. 129:705-733. https://doi .org/10.1007/s00418-008-0435-6.

Osorio, J. S., R. L. Wallace, D. J. Tomlinson, T. J. Earleywine, M. T. Socha, and J. K. Drackley. 2012. Effects of source of trace minerals and plane of nutrition on growth and health of transported neonatal dairy calves. J. Dairy Sci. 95:5831-5844. https://doi.org/ 10.3168/jds.2011-5042.

Rosa, F., S. Busato, F. C. Avaroma, K. Linville, E. Trevisi, J. S. Osorio, and M. Bionaz. 2018. Transcriptional changes detected in fecal RNA of neonatal dairy calves undergoing a mild diarrhea are associated with inflammatory biomarkers. PLoS One 13:e0191599. https://doi.org/10.1371/journal.pone.0191599.

Rosa, F., and J. S. Osorio. 2019. Short communication: Comparative gene expression analysis on the enrichment of polymorphonuclear leukocytes and gastrointestinal epithelial cells in fecal RNA from nondiarrheic neonatal dairy calves. J. Dairy Sci. 102:7464-7468. https://doi.org/10.3168/jds.2018-16074.

Saqui-Salces, M., Z. Huang, M. F. Vila, J. Li, J. A. Mielke, P. E. Urriola, and G. C. Shurson. 2017. Modulation of intestinal cell differentiation in growing pigs is dependent on the fiber source in the diet. J. Anim. Sci. 95:1179-1190. https://doi.org/10.2527/ jas2016.0947.

Schroyen, M., A. Stinckens, R. Verhelst, M. Geens, E. Cox, T. Niewold, and N. Buys. 2012. Susceptibility of piglets to enterotoxigenic Escherichia coli is not related to the expression of MUC13 and MUC20. Anim. Genet. 43:324-327. https://doi.org/10.1111/j .1365-2052.2011.02241.x.

Sehested, J., L. Diernaes, P. Detlef Møller, and E. Skadhauge. 1999. Transport of butyrate across the isolated bovine rumen epithelium-interaction with sodium, chloride and bicarbonate. Comp. Biochem. Physiol. A Mol. Integr. Physiol. 123:399-408. https:// doi.org/10.1016/S1095-6433(99)00082-3.

Sharma, A. K., B. Pafčo, K. Vlčková, B. Červená, J. Kreisinger, S. Davison, K. Beeri, T. Fuh, S. R. Leigh, M. B. Burns, R. Blekhman, K. J. Petrželková, and A. Gomez. 2019. Mapping gastrointestinal gene expression patterns in wild primates and humans via fecal RNA-seq. BMC Genomics 20:493. https://doi.org/10.1186/s12864 -019-5813-z.

Shen, Z., H. M. Seyfert, B. Löhrke, F. Schneider, R. Zitnan, A. Chudy, S. Kuhla, H. M. Hammon, J. W. Blum, H. Martens, H. Hagemeister, and J. Voigt. 2004. An energy-rich diet causes rumen papil- lae proliferation associated with more IGF type 1 receptors and increased plasma IGF-1 concentrations in young goats. J. Nutr. 134:11-17. https://doi.org/10.1093/jn/134.1.11.

Smathers, R. L., and D. R. Petersen. 2011. The human fatty acidbinding protein family: Evolutionary divergences and functions. Hum. Genomics 5:170-191. https://doi.org/10.1186/1479-7364-5 $-3-170$.

Steele, M. A., G. B. Penner, F. Chaucheyras-Durand, and L. L. Guan. 2016. Development and physiology of the rumen and the lower gut: Targets for improving gut health. J. Dairy Sci. 99:4955-4966. https://doi.org/10.3168/jds.2015-10351.

Stevenson, B. R., J. D. Siliciano, M. S. Mooseker, and D. A. Goodenough. 1986. Identification of ZO-1: A high molecular weight polypeptide associated with the tight junction (zonula occludens) in a variety of epithelia. J. Cell Biol. 103:755-766. https://doi.org/ $10.1083 /$ jcb.103.3.755.

Storch, J., and A. E. A. Thumser. 2000. The fatty acid transport function of fatty acid-binding proteins. Biochim. Biophys. Acta 1486:28-44. https://doi.org/10.1016/S1388-1981(00)00046-9.

Thumser, A. E., J. B. Moore, and N. J. Plant. 2014. Fatty acid binding proteins: Tissue-specific functions in health and disease. Curr. Opin. Clin. Nutr. Metab. Care 17:124-129. https://doi.org/10 .1097/MCO.0000000000000031.

Van Itallie, C. M., A. S. Fanning, A. Bridges, and J. M. Anderson. 2009. ZO-1 stabilizes the tight junction solute barrier through coupling to the perijunctional cytoskeleton. Mol. Biol. Cell 20:39303940. https://doi.org/10.1091/mbc.e09-04-0320.

Vandesompele, J., K. De Preter, F. Pattyn, B. Poppe, N. Van Roy, A. De Paepe, and F. Speleman. 2002. Accurate normalization of real-time quantitative RT-PCR data by geometric averaging of multiple internal control genes. Genome Biol. 3:research0034.1.

Walker, M. P., C. M. Evock-Clover, T. H. Elsasser, and E. E. Connor. 2015. Short communication: Glucagon-like peptide-2 and coccidiosis alter tight junction gene expression in the gastrointestinal tract of dairy calves. J. Dairy Sci. 98:3432-3437. https://doi.org/ 10.3168/jds.2014-8919.

Wells, J. M., R. J. Brummer, M. Derrien, T. T. MacDonald, F. Troost, P. D. Cani, V. Theodorou, J. Dekker, A. Méheust, W. M. de Vos, A. Mercenier, A. Nauta, and C. L. Garcia-Rodenas. 2017. Homeostasis of the gut barrier and potential biomarkers. Am. J. Physiol. Gastrointest. Liver Physiol. 312:G171-G193. https://doi.org/10 .1152/ajpgi.00048.2015.

Whitfield-Cargile, C. M., N. D. Cohen, K. He, I. Ivanov, J. S. Goldsby, A. Chamoun-Emanuelli, B. R. Weeks, L. A. Davidson, and R. S. Chapkin. 2017. The non-invasive exfoliated transcriptome (exfoliome) reflects the tissue-level transcriptome in a mouse model of NSAID enteropathy. Sci. Rep. 7:14687. https://doi.org/10.1038/ s41598-017-13999-5.

Wiercinska-Drapalo, A., J. Jaroszewicz, E. Siwak, J. Pogorzelska, and D. Prokopowicz. 2008. Intestinal fatty acid binding protein (IFABP) as a possible biomarker of ileitis in patients with ulcerative colitis. Regul. Pept. 147:25-28. https://doi.org/10.1016/j.regpep 2007.12.002.

Yu, C., G. Jia, Y. Jiang, Q. Deng, Z. Chen, Z. Xu, X. Chen, and K. Wang. 2014. Effect of glucagon-like peptide 2 on tight junction in jejunal epithelium of weaned pigs though MAPK signaling pathway. Asian-Australas. J. Anim. Sci. 27:733-742. https://doi.org/ 10.5713/ajas.2013.13540.

\section{ORCIDS}

F. Rosa (ㄴ) https://orcid.org/0000-0002-8906-4056

S. Busato $\odot$ https://orcid.org/0000-0002-2542-3443

R. Mohan ๑ https://orcid.org/0000-0002-0947-4363

N. Carpinelli @ https://orcid.org/0000-0003-1208-8671

M. Bionaz @ https://orcid.org/0000-0002-0674-1892

J. S. Osorio (ํ) https://orcid.org/0000-0001-6192-0917 